\title{
Contra-cartografias de povos tradicionais nas metrópoles paraenses: repertórios para um urbano amazônico plural
}

Counter-cartographies of traditional peoples in the metropolises of Pará: repertoires for a plural Amazonian urban

\author{
Ana Claudia Cardoso ${ }^{1}$ \\ Maria do Socorro Amoras ${ }^{2}$ \\ Solange Gayoso ${ }^{3}$ \\ Harley Silva ${ }^{4}$
}

\section{Resumo:}

Este texto analisa dados sobre como são apropriados e gerenciados coletivamente territórios de comunidades que manifestam aspectos da transição urbano/periurbano/rural em duas regiões metropolitanas paraenses: Belém e Santarém, a partir de resultados parciais da pesquisa intitulada "Alternativas de Desenvolvimento: cartografia social de territórios de populações tradicionais do Pará e Minas Gerais". Trata-se de uma contra-cartografia para territórios periurbanos e periféricos, construída a partir de narrativas próprias dessas comunidades. A metodologia se valeu da pesquisa participante, tomando como interlocutor e pesquisador os discentes/bolsistas da pesquisa, nativos dessas comunidades, contemplados pela política de cotas raciais, e pelos demais discentes/bolsistas e pesquisadores envolvidos com as lutas desses grupos. As primeiras investidas no campo possibilitaram mapear e compreender aspectos históricos, geográficos e socioterritoriais presentes na dinâmica da organização social e política de comunidades tradicionais (indígenas, quilombolas, ribeirinhas) e camponesas assentadas. As reflexões apontaram que esses territórios vivenciam conflitos diversos, internos e externos, e mantêm estratégias de resistência para enfrentar tensões resultantes das dimensões materiais e imateriais, provocadas por processos que desencadeiam situações de ameaças de perda do espaço habitado, abandono dos seus modos de vida e a inserção de seus membros como subalternizados na sociedade urbana. $O$ modo como lutam para serem reconhecidos, expressa territorilidades específicas dessas comunidades, as quais desmontam visões estáticas e essencializadas acerca desses povos.

Palavras-chave: Contra-cartografia; decolonialidade; povos tradicionais; Região Metropolitana de Belém; Região Metropolitana de Santarém.

\section{Abstract:}

This paper analyzes data on how territories of communities that manifest aspects of the urban/peri-urban/rural transition are collectively appropriated and managed

\footnotetext{
${ }^{1}$ E-mail: acardoso@ufpa.br

2 E-mail: samoras@ufpa.br

3 E-mail: solgayoso@ufpa.br

4 E-mail: harleysilva@ufpa.br
} 
in two metropolitan regions of Pará: Belém and Santarém.It is based on partial results of the research entitled "Alternatives of Development: social cartography of territories of traditional populations of Pará and Minas Gerais". It is a countercartogtaphy for peri-urban and peripheral territories, built from the narratives of these communities. The methodology is based on participant research, taking as interlocutor and researcher the students/grantees of the research, natives of these communities, contemplated by the policy of racial quotas, and other students/grantees and researchers involved with the struggles of these groups. The first explorations in the field enabled the mapping and understanding of historical, geographical and socio-territorial aspects present in the dynamics of social and political organization of traditional communities (indigenous, maroons, riverine) and peasant settlers. The reflections pointed out that these territories experience various conflicts, internal and external, and maintain resistance strategies to face tensions resulting from material and immaterial dimensions, caused by processes that trigger situations of threats of loss of inhabited space, abandonment of their ways of life and the insertion of their members as subalternized in urban society. The way they struggle to be recognised expresses the specific territorialities of these communities, which dismantle static and essentialised views of these peoples.

Keywords: Counter-cartography; decoloniality; traditional peoples; Metropolitan Region of Belém; Metropolitan Region of Santarém.

\section{À guisa de introdução: por uma contra-cartografia em defesa da luta política pela representação da diversidade}

A década de 1990 foi um marco na difusão de movimentos populares contra as grandes narrativas culturais, políticas e científicas. Elas foram reconhecidas como instrumentais para a justificativa dos discursos hegemônicos em favor de formas de viver de sociedades ocidentais, particularmente em suas versões urbano-industriais (ARES; RISLER, 2013). Essas narrativas atingiram de modo particularmente intenso regiões de grande diversidade social e ambiental, como a PanAmazônia, ao promoverem a inferiorização dos povos, o silenciamento de atores sociais e o apagamento dos registros de suas múltiplas formas de vida, tanto daqueles que viviam nas cidades, quanto de outros que habitavam o espaço rural;deixando-o, desse modo, cada vez mais apropriado para a produção de commodities (HALDER, MICHEL, 2018; ALMEIRA, DOURADO, BERTOLINI, 2018).

Neste período, a difusão de tecnologias e ferramentas, tais como o georreferenciamento e geoprocessamento, tornou possível a produção de representações com a perspectiva de grupos sociais camponeses, indígenas e tradicionais em países sulamericanos, em contraponto àquelas produzidas pelas instituições oficiais ou pela mídia de massa, sob o comando de instituições políticas e econômicas, para fazer a opinião pública acreditar em uma única narrativa possível a respeito do território. Não por acaso tais narrativas oficiais eram comprometida com os interesses de mercado (ARES; RISLER, 2013), dentro do ideário do desenvolvimentismo.

No Brasil, destaca-se a experiência da produção da Nova Cartografia Social da Amazônia que, sistematicamente, expõe conflitos territoriais de comunidades a partir de narrativas e registros desenvolvidos por elas mesmas. As cartografias produzidas contemplam uma diversidade de situações sociais que chamam atenção para um processo de afirmação identitária bastante diversa, apresentando critérios étnicos e identitários próprios de cada grupo, que tem seu território mapeado, com uso de 
conhecimentos cartográficos elementares, segundo modalidades de interpretação desenvolvidas em trabalhos de pesquisa/extensão.

Para Ares e Risler (2013), as cartografias oficiais são representações ideológicas. Historicamente elas têm servido para facilitar a apropriação de territórios e da riqueza nele existente. Nesta condição de instrumento de dominação também naturalizam a conversão de áreas rurais ou de floresta para os usos e as estratégias próprias da produção capitalista, inclusive a produção da cidade. Os sistemas produtivos da Amazônia, de organização mercantil e base extrativista, por séculos favoreceram um intenso fluxo entre a cidade e sua hinterlândia. Em função de suas características produtivas e institucionais esses sistemas econômicos criaram limites difusos entre áreas urbanas e o entorno, ou seja, faixas periurbanas nas quais com frequência existiam vilas e comunidades. Com a intensificação da urbanização, esses territórios têm sido incorporados como parte de "manchas urbanas", constituindo territórios urbanos que possuem uma diversidade social e ambiental que destoam das imagens hegemônicas quando submetidos ao enquadramento territorial produzido a partir das definições e normas oficiais (GOMES; CARDOSO, 2018; CARDOSO et al, 2018; CARDOSO, MELO, GOMES, 2017).

A desarticulação entre as representações oficiais e a realidade cotidiana de grupos vistos como diferentes, no sentido de inferior, sob a perspectiva da vida metropolitana, torna crucial a produção de contra-cartografias, entendidas como representações que expressem a apropriação do território sob outras perspectivas ou visões de mundo, que dialoguem com a linguagem, símbolos e formas de representação dos diversos grupos sociais. Esse movimento vem se consolidando nas formulações de autores decoloniais e mais ainda daqueles anti-coloniais (que se opõem à colonização), como é o caso da socióloga boliviana Silvia Cusicanqui, que destaca a insurgência de grupos sociais e de povos subalternizados como estratégia de denúncia da violência simbólica a eles imposta pelas representações hegemônicas e oficiais (CUSICANQUI, 2015). Como já mencionado, as narrativas hegemônicas sobre esses povos (e grupos) desqualificam suas cosmovisões por não serem técnicas, ou adequadas aos códigos vigentes que dominam os campos científico, político, econômico e religioso.

Nesta perspectiva, este texto apresenta resultados parciais da pesquisa "Alternativas de Desenvolvimento: cartografia social de territórios de populações tradicionais do Pará e Minas Gerais". Os casos paraenses e mineiros são distintos dos paraenses. Em Minas Gerais o estudo foi dedicado somente a dois casos de comunidades indígenas; há o caso do território Xakriabá localizado no norte de Minas Gerais, e que é tomado como o mais consolidado, referência de grande autonomia e capacidade de mobilização dos indígenas (MONTE-MOR, GOMES, 2020), e o caso dos indígenas que vivem na região Metropolitana de Belo Horizonte e ainda lutam para constituir novos territórios em condições muito mais difíceis (CAMPOS, 2019). No Pará, o projeto foi dedicado à produção de registros de como se formam, são apropriados e gerenciados coletivamente territórios de comunidades que manifestam aspectos da transição urbano/periurbano/rural em duas regiões metropolitanas paraenses - as Regiões Metropolitanas de Belém e Santarém (RMB e RMS), conforme indicado nas figuras 1 e 2 . Trata-se da construção de uma contracartografia para territórios periurbanos e periféricos dessas regiões, pautada pela narrativa das próprias comunidades (que podem ser indígenas, quilombolas, ribeirinhas ou de assentados em territórios de refoma agrária), ou seja, o foco está nas narrativas contra hegemônicas, tornadas possíveis por meio da participação dos discentes/bolsistas da pesquisa nativos dessas comunidades e pelos demais discentes/bolsistas envolvidos com as lutas desses povos (e grupos). 


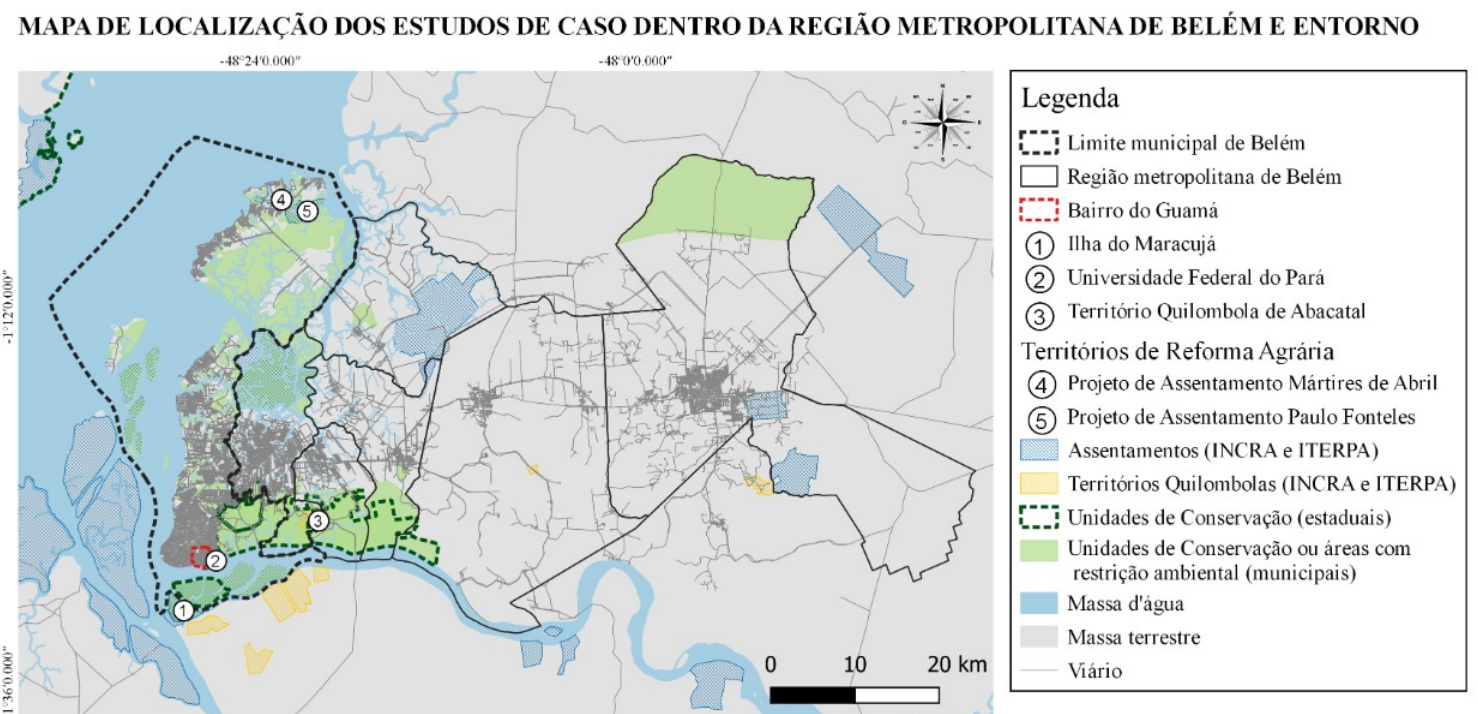

EPSG:4674 - SIRGAS 2000 - Geográfico. Fonte: IBGE (2019a); IBGE (2019b); IDERFLOR-BIO (2019); INCRA (2019a); INCRA (2019b); ITERPA (2019a). Elaboracão: Leticia Ribeiro Vicente. Data: 28/06/2020.

Figura 1: áreas de estudo em Belém e Ananindeua, parte da Região Metropolitana de Belém (RMB). Fontes e elaboração já indicados na imagem.

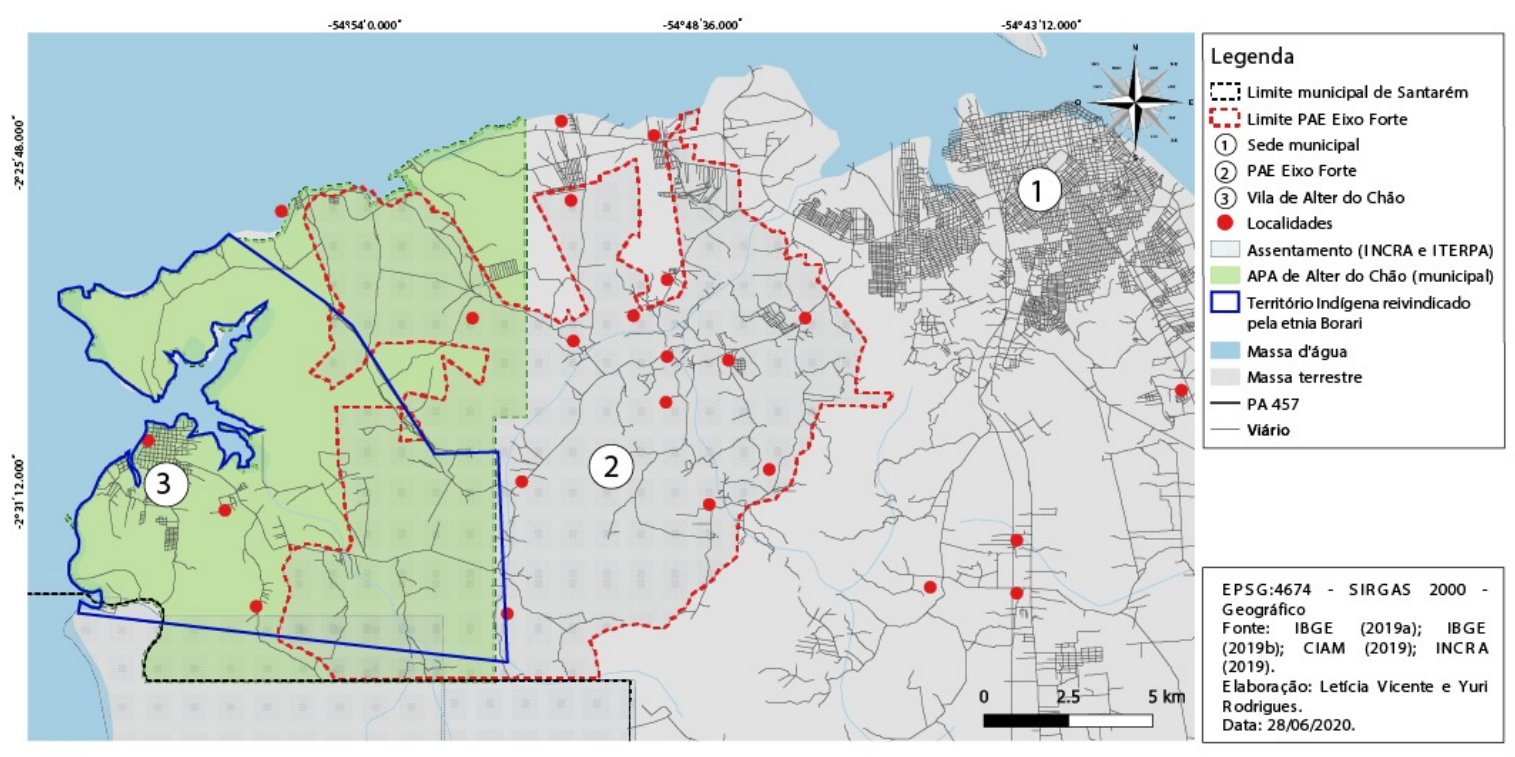

Figura 2: áreas de estudo em Santarém - recorte da Região Metropolitana de Santarém (RMS), território reivindicado pelo povo Borari destacado em azul. Fonte e elaboração indicados na imagem.

A pesquisa busca a representação dos conflitos, perdas e injustiças socioambientais relacionados ao processo de urbanização extensiva, que: a) por um lado sujeitam tais comunidades à forte influência de padrões de consumo, regras ou atividades ligadas ao modo de vida urbano industrial, dada a proximidade com as cidades e à fluidez histórica do relacionamento urbano rural na região (CARDOSO et al, 2018); e b). Por outro lado, promovem sua assimilação pelas periferias, condenando-as por meio da carência de políticas públicas a uma crescente incerteza sobre a sua permanência e sua capacidade de produção e reprodução da vida a partir da gestão dos recursos do território. As tensões resultantes das dimensões materiais e imateriais desse processo alimentam a tendência de conversão e abandono do modo de vida dessas comunidades e a inserção de seus membros como subalternizados na sociedade urbana. 
Em termos metodológicos, lidar com tais tensões na busca de compreensões sobre esses grupos requer esforços de descolonização do pensamento e do conhecimento, para descontaminá-los de valores e interesses hegemônicos. Cusicanqui (2015) destaca a importância da observação ao longo do processo de investigação, ou seja, a pesquisa em profundidade, pois a detecção dos conflitos territoriais exige tempo para consulta dos registros acumulados (orais, iconográficos, documentais), de modo a permitir o desenvolvimento de narrativas de vida e dos processos que as afetam. Esta estratégia facilita a detecção das invisibilidades (ex.: de gênero), de contradições, transitoriedades e simultaneidades. A autora defende a posição radical de recusa de aceitação do híbrido, ou da acomodação de opostos (fusão) em uma síntese (dialética), para evitar a perda dos registros e o mascaramento das contradições latentes dentro e entre comunidades.

Mais do que enquadrar a realidade segundo grandes categorias como urbano e rural, formal e informal, seria necessário explicitar as co-existências e oposições (uma pessoa pode viver e trabalhar na cidade e continuar atuando em uma atividade considerada rural como a agricultura, pesca ou extrativismo de coleta dentro da cidade).Para detectar as co-existências seria necessário observar a realidade: a) com o olhar periférico, b) a partir de um diálogo com o passado e, c) a partir dos silêncios. Nesta perspectiva, Ocanã e López (2019) também recomendam: a) o contemplar comunitário, b) o diálogo solidário - que coloca o outro como igual, e c) a reflexão pautada em um sentir e pensar coletivo, capaz de rever crenças e evitar a apropriação privada do conhecimento. Desse modo, o pensamento e a ação teriam maior potência.

A partir desse intuito, este texto refere-se ao desenho interdisciplinar (envolvendo contribuições das áreas de arquitetura e urbanismo, antropologia, economia e serviço social) de uma pesquisa conduzida durante o isolamento social, imposto pela pandemia de Covid-19. As limitações levaram à associação de tecnologias digitais ao trabalho dos estudantes já inseridos nas comunidades para que, por meio da escuta deles, fosse possível tornar conhecidas as formas de resistência em territórios interculturais com identidades múltiplas (indígena/ribeirinha/quilombola) aos problemas desencadeados pelas pressões da urbanização.

Esta estratégia beneficiou-se da política de cotas, que permitiu o ingresso de pessoas indígenas, quilombolas, ou em condição de vulnerabilidade social ao ambiente acadêmico, tornando-os pesquisadores e interlocutores preferenciais dentro de suas comunidades, e assumindo-os como representantes de suas comunidades no diálogo do grupo de pesquisa. Outro aspecto relevante do desenho da pesquisa é a promoção da interação entre as comunidades estudadas para discussão de processos e problemas comuns, e também com outras semelhantes no país, já que a pesquisa conta com casos parceiros em Minas Gerais. Nesta formação em rede, a diversidade de visões de mundo e de práticas sociais, econômicas e ambientais, presentes dentro das duas regiões metropolitanas,é acionada como uma possibilidade de diálogo entre narrativas diversas.

\section{Sobre a diversidade socioterritorial em áreas metropolitanas}

A concepção de território vem sendo utilizada por diferentes agentes sociais, e segue em permanente disputa. Tal disputa teórica e prática, na apropriação da categoria território, possibilitou a construção de outras percepções sobre os espaços vividos, que abrangem as formas de apropriação e uso territorial por quem nele habita. A forma de habitar esses espaçosé estruturante da identidade do território. É, portanto, o modo como as territorialidades específicas de cada grupo social são produzidas.

As territorialidades específicas, nesse sentido, exprimem os elementos identitários de seus agentes. Isso significa dizer que as territorialidades são dinâmicas e não herméticas. $E$ elas são um conjunto de possibilidades e não um dado a priori, invariante, uma categoria homogênea, socialmente determinada e 
determinante dos comportamentos e das disposições subjetivas dos indivíduos. O território pressupõe movimento. Ele possui dimensão histórica, pois se estrutura, se constrói e cria sua identidade a partir das relações sociais estabelecidas nas trocas e disputas entre os diferentes agentes sociais envolvidos. A trajetória do território reflete e se interliga às trajetórias daqueles que nele vivem.

Os processos de territorialização incluem a compreensão de território a partir das formas de uso e apropriação do grupo social assumida a noção de que a ação sobre a natureza se "realiza a partir da natureza valorada pela sociedade" (SANTOS,1999:18), relação a partir da qual se inicia uma dialética sociedade-natureza. E, por isso, trata-se de território com conteúdo social, no lugar de interpretações que dão conta apenas das divisões político-administrativas e ignoram a dinâmica sócio-territorial fundada na existência.Sob esta perspectiva, a noção de território encerra mudanças e processo, como formaconteúdo.

Nas cidades é possível observar que as diferenças locais são aprofundadas pelas desigualdades, as quais são acirradas pelos conflitos e pela violência que conformam o poder catalisador sobre esses grupos que buscam hegemonizá-los.E ainda, ao contrário da tão difundida idéia de arrefecimento e morte do Estado, este se impõe com força na viabilização de interesses econômicos, financeiros e políticos da classe econômica (SANTOS, 2000), assumindo violentamente a face de um Estado capitalista neoliberal, de (necro)políticas nacionais / locais que nega a existência de povos e comunidades tradicionais ao não reconhecer a (re)existência em seus territórios. Como exemplos dessas negações pode-se listar as especificidades invisibilizadas dos povos ribeirinhos e quilombolas residentes nas comunidades tradicionais e ilhas da RMB e de extrativistas e indígenas da RMS, situações referidas no próximo item.

A organização social dos territórios tradicionalmente ocupados é agenciada por cosmologias, cosmovisões e epistemes que acionam saberes e práticas, a moral e a ética de uma forma de existir ancestral. São conhecimentos dinamizados nas relações intergeracionais e cotidianas. Assim, a cultura é atualizada e modificada no tempo. Esses elementos de pertença são ativados na mobilidade que esses grupos imprimem no espaço habitado, sendo expressivos das relações simbólicas que orientam suas defesas políticas por um modo de ser e de viver. Compreende-se, desse modo, que esses grupos são dinâmicos e diversos, com identidades coletivas em construção.

A diversidade está na forma de interagir com a natureza pelo trabalho individual e coletivo, contudo, não é possível generalizar os efeitos e a maneira como criam suas estratégias de subsistir nesses lugares, pois o modo como lidam com as circunstâncias materiais que lhes são impostas também é movido de acordo com as suas concepções políticas sobre o território. Reconhecer a diversidade, nesse sentido, é compreender a autonomia de um esquema da ancianidade do grupo, ou seja, a sua genealogia que os ajuda a analisar as gerações e suas experiências sociais em torno de um modo de vida singular nesses lugares.

A relação de parentesco, desse modo, é estruturante da identidade dos membros dessas populações, está estreitamente vinculada à transmissão de saberes na organização sócioterritorial e seus critérios de pertencimento estabelecidos. Como argumenta Almeida (2002), o sentimento de pertença desses agentes não se apóia em provas documentais e arquivísticas da instrumentalidade jurídica moderna.

As relações simbólicas movimentadas por um conjunto de saberes definem processos de afirmação étnica e política. É a forma como acionam seus esquemas convencionais e os conformam às suas necessidades, buscando novas categorias, atribuindo sentidos e significados ao lugar habitado. A compreensão do que Ihes fazem diversos exige, assim, o entendimento das circunstâncias em que intercambiam saberes, valores, arranjos e rearranjos particulares na relação com a natureza e com o Estado. São longos processos de conflitos históricos travados com agentes externos. Por isso, são necessários entendimentos que alcancem as lógicas, as estratégias políticas de sobrevivência dessas comunidades; que sejam 
capazes de expressar como elas se colocam hoje, ou como elas se autodefinem e desenvolvem suas práticas de interlocução, em meio a processos de territorialização.

Neste sentido, é oportuno esclarecer que o processo de territorialização é resultante de uma conjunção de fatores, que envolve a capacidade mobilizatória em torno de uma política de identidade e certo jogo de forças em que os agentes sociais, através de suas expressões organizadas, travam lutas e reivindicam direitos face ao Estado. As relações comunitárias neste processo também se encontram em transformação, descrevendo a passagem de uma unidade afetiva para uma unidade política de mobilização ou de uma existência atomizada para uma existência coletiva. A chamada "comunidade tradicional" se constitui nesta passagem. O significado de "tradicional" mostra-se, deste modo, dinâmico e como um fato do presente, rompendo com a visão essencialista [...] Tal territorialidade consiste numa forma de interlocução com antagonistas e com o poder do estado" (ALMEIDA, 2006, p. 88-89). Viver do sustento do lugar e no lugar do sustento confere a esses grupos singularidades pela forma como articulam suas redes de conhecimentos.

Segundo Almeida (2008, p. 40): "Trata-se, em resumo, de um capítulo do processo de politização da natureza e da emergência de uma vívida autoconsciência cultural apoiada em conhecimentos imateriais que nutrem as unidades de cálculo do processo de produção permanente (tamanho da área de plantio, sua localização distante das margens dos cursos d'água e das nascentes, tempo de encapoeiramento, cuidados durante o preparo da área de cultivo para evitar a derrubada de determinadas espécies vegetais, uso seletivo dos recursos florestais, etc.)".

Sustentar-se do lugar habitado também é uma medida de equilíbrio biótico, em termos de possibilidades de subsistência e reprodução social; uma forma de subsistir entre estabilidades e mudanças. Por meio de epistemes da ancestralidade, acionadas para habitar seus lugares, estabelecem um diálogo histórico com o legado desses povos para afirmar suas identidades e suas práticas expressivas dos conhecimentos agroflorestal e telúrico, os quais não se desvinculam de suas religiosidades e crenças. Assim, a partir de um "modo de estar no mundo", mapeiam as suas fronteiras étnicas e criam estratégias de atualização dos seus saberes, ou seja, daquilo que lhes fazem diversos.

Em acordo com Bhabha (1998), a diversidade cultural aqui pensada não diz respeito às identificações fixas de sujeitos na cultura, ancora-se na perspectiva da diferença cultural e suas interconexões na contemporaneidade, entre-lugares das identidades específicas. O deslocamento do entendimento da diversidade cultural para a compreensão da diferença cultural produz uma cisão no modo de entender o tempo presente a partir de espaços plurais e enunciadores de reterritorializações. Nesse sentido, rompese com naturalizações binárias atribuídas a esses povos e populações e com a oposição sujeito/objeto, sujeito/cultura.

A compreensão dessa ruptura trás para este estudo os questionamentos levantados por Bhabha (1998, p.20): de que modo esses sujeitos se tornam o que são nos entre-lugares? O que negociam e tomam para si daquilo que excede da soma das partes da diferença (aquelas já conceituadas como raça/classe/gênero, e outras)? De que modo chegam a formular estratégias de representação ou aquisição de poder no interior de pretensões concorrentes intra e entre comunidades? Esses grupos apesar de histórias e trajetórias comuns de exclusão, privação, exploração e discriminação, o que acionam como valores e interesses, significados e prioridades, pode nem sempre ser colaborativo e dialógico, evidenciando antagonismos e conflitos internos e externos desmedidos.

É a produção, contudo, dessas diferenças que acionam lugares de negociação cultural, deslocando, assim, a reflexão epistemológica sobre a fixidez dos binarismos do sujeito com traços culturais e étnicos pré-estabelecidos, inscritos na tradição, para um lugar enunciativo, de uma prática enunciativa (BHABHA, 1998). Assim, povos subalternizados têm tomado o lugar da discriminação social e os deslocamentos culturais para afirmar suas tradições culturais, recuperar histórias de opressões e exclusões, serem 
reconhecidos, enfim, reivindicar o direito de serem nomeados nas suas diferenças e especificidades, ou seja, naquilo que lhes fazem diversos.

\section{3. $O$ contexto espacial das práticas cotidianas na RMB}

Belém é uma metrópole amazônica de 404 anos, com uma formação sócio espacial diversa. O município é dividido em uma porção continental e aproximadamente quarenta ilhas que compreendem $66 \%$ do território do município. A região metropolitana é composta por outros seis municípios e possui amplas áreas periféricas. Na porção não insular, as áreas urbanas de terras firme foram originalmente apropriadas pelas elites coloniais e seus herdeiros. Essas ocupações geralmente aconteceram segundo cânones do urbanismo português (pré e pós reconstrução de Lisboa), enquanto as várzeas foram ocupadas por usos rurais praticados pelos migrantes nativos da região, que sabiam manejar a biodiversidade e o ciclo das águas (hortas, espaços de extrativismo e criação de animais, trapiches, etc.). É importante refletir que o projeto colonial nas cidades da Amazônia, seja na área insular ou na terra firme, não se desenvolveu sem a resistência dos grupos explorados, os registros e evidências advindos de periferias e áreas periurbanas são territórios prenhes de suas ancestralidades. São lugares onde circulam saberes e práticas contra hegemônicos.

Miranda (2020) sistematizou informações demográficas de 1872 e constatou que $55,79 \%$ da população de Belém era composta por não brancos (pardos, negros, caboclos) e destacou o quanto este fato é omitido da narrativa de cidade branca do ciclo da borracha, quando os padrões europeus de serviço (provisão de energia, transporte e saneamento) eram tomados como referência inclusive com a contratação de concessionárias europeias para a provisão destes serviços (SARGES, 1998).

Esta visão demográfica deve ser articulada a outra, de natureza econômica: a importância histórica da atividade extrativa e da agricultura praticada pelas chamadas populações caboclas na economia amazônica. Não obstante a literatura de história econômica tenha atribuído rótulos depreciativos e associado sua prática a uma condição de pobreza atávica, as atividades extrativistas e os grupos que a praticaram, foram historicamente o fundamento da economia amazônica. Como mostra Costa (2019) há abundante material empírico que corrobora essa hipótese, enquanto as afirmações sobre pobreza e estagnação das economias extrativas foram geralmente feitas de modo dogmático. Essa condição chave do extrativismo na economia da região veio a se interromper apenas com as mudanças drásticas introduzidas pelos governos militares. Neste período se introduziram na região condições inteiramente novas para a prática de monocultura, agropecuária, além da mineração, todas essas com base em pesado investimento estatal (BECKER,2005).

As atividades extrativistas continuam importantes na economia da Amazônia, particularmente (embora não exclusivamente) pela criação de oportunidades de trabalho e renda na economia popular. Segundo o Boletim do Observatório Paraense do Mercado de Trabalho, no quarto semestre de 2019 havia 66\% da população ocupada no Estado do Pará trabalhava na economia informal. Essa cifra é hoje bastante superior à média que no país é de $47,4 \%$, o que é uma condição historicamente forte na Amazônia (LEÃO, 2020). Para esta discussão, é importante destacar que grande parcela desta economia informal é ligada ao manejo de recursos naturais (produtos não madeireiros, frutos, agricultura familiar e pesca) e que depende da existência de rios e florestas e do direito de acesso a um território de produção (BARTOLI 2018; SILVA, DINIZ, FERREIRA,2013). 


\subsection{Os territórios insulares dos quilombolas ribeirinhos da llha do Maracujá e dos assentamentos de reforma agrária da llha do Mosqueiro}

Territórios com tais atributos lutam pela preservação nas ilhas de Belém e Ananindeua, onde ocorrem as maiores concentrações de vegetação nativa do espaço metropolitano (CARDOSO, BRAZIL, CARDOSO, 2021). Em Belém, as ilhas são consideradas majoritariamente rurais e, após a ocupação das várzeas do continente por grupos sociais excluídos, tornaram-se alternativas de moradia para população assalariada que não consegue arcar com o custo da moradia no continente, ou como espaço de reserva para a construção de condomínios de luxo (caso do Alphaville construído sobre zona de proteção ambiental na ilha de Caratateua), conforme a disponibilidade de acesso por ponte ou por transporte público regular.

As ilhas são territórios sub-representados em todas as estatísticas e políticas públicas (VICENTE, 2019). Durante séculos a porção seca das ilhas maiores foi destinada a usos de interesse da metrópole (presídio, colônias agrícolas), suas praias foram ocupadas por casas de final de semana, enquanto suas várzeas se mantiveram como território de populações extrativistas. Atualmente esse mesmo assédio se estende às ilhas de várzea, como a llha do Combu, localizada a $1,5 \mathrm{~km}$ do continente, que sofrem impacto da poluição do continente, do turismo e da gentrificação das margens dos rios, por grupos que procuram casas de final de semana e compram do ribeirinho a posse da margem do rio, promovendo um adensamento da ocupação, redução da área de produção das famílias, pressão por novos usos e desestruturação do modo de vida dos nativos (BRITO, 2018), ao mesmo tempo em que a produção extrativista é valorizada pelos circuitos da gastronomia regional.

A llha do Maracujá (ver número 1 na figura 3) localiza-se atrás da llha do Combu (ver número 3 na figura 3), e está em uma situação de indefinição de pertencimento entre os municípios de Belém e Acará por falta de recursos tecnológicos na época de definição de limites entre estes municípios (SILVA; TOURINHO, 2017). A comunidade da llha do Maracujá afirma-se no território, acionando a ancestralidade de uma população, que se declara ribeirinha (pescadora) e passa por um processo de reconhecimento como comunidade quilombola (de agricultores, tal como seus ancestrais), já que boa parte de sua população descende dos Territórios Quilombolas de Santa Quitéria e Itacoãzinho, localizadas em solos de terra firme do município do Acará. São, portanto, identidades múltiplas, acionadas na luta pelo reconhecimento do lugar do pertencimento.

A população da ilha instalou energia elétrica com seus próprios meios, e está mobilizada para a instalação de uma rede de abastecimento de água. Carece de soluções de saneamento e de um serviço de telefonia de qualidade. O avanço para o ensino médio demanda o deslocamento para a Belém continental assim como o escoamento da produção de palmito, açaí e frutas, que são vendidas nas feiras da cidade. A figura 3 ilustra os fluxos mais importantes de mercadorias e população entre a ilha e acidade. A organização do novo quilombo na llha do Maracujá (COSTA, 2020)permitiu que membros da comunidade pudessem ter acesso à universidade pública por meio da política de cotas. 


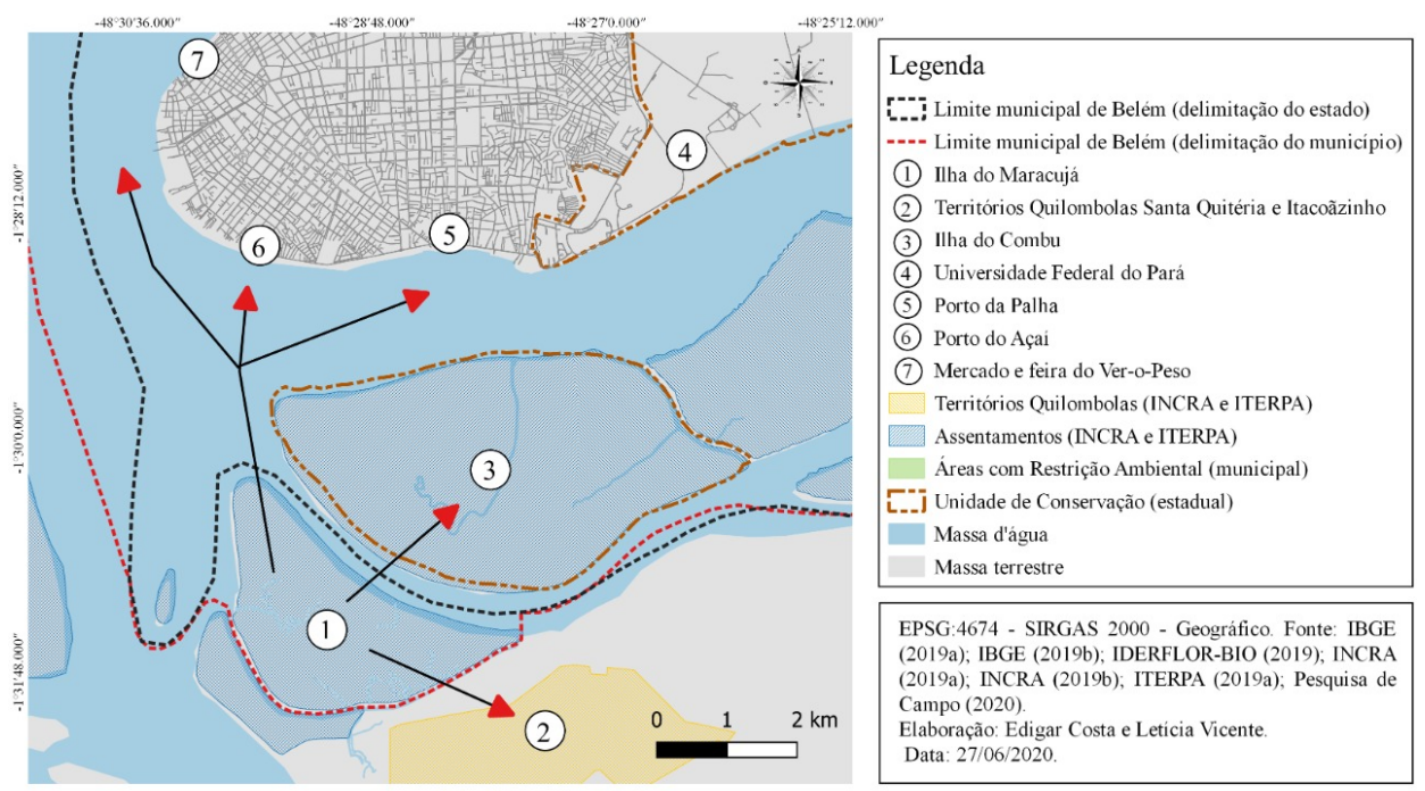

Figura 3 - Localização e fluxos principais dos moradores da llha do Maracujá. Fontes e elaboração já indicadas na figura

Em Belém assentamentos de reforma agrária, na ilha do Mosqueiro, também lutam para afirmar seus pertencimentos identitários ligados a grupos rurais. Os assentados se reconhecem como agricultores, mas se veem como um grupo estigmatizado dentro da llha (GONZAGA, 2020). A localização dos assentamentos próxima a bairros já consolidados gera pressões para conversão de uso das terras do assentamento que margeiam a rodovia, (ver figura 4). Essa localização também redireciona as expectativas das novas gerações dentro das famílias ampliadas, que por falta de oportunidade de acesso à terra compartilha e divide o lote de produção para usos urbanos e rurais (figura 5). Também merece destaque a prática do trabalho sazonal no turismo, que por um lado permite a venda de produtos do lote em barracas na praia (ex.: açaí), e por outro concorre com a produção e comercialização de alimento agroecológico.

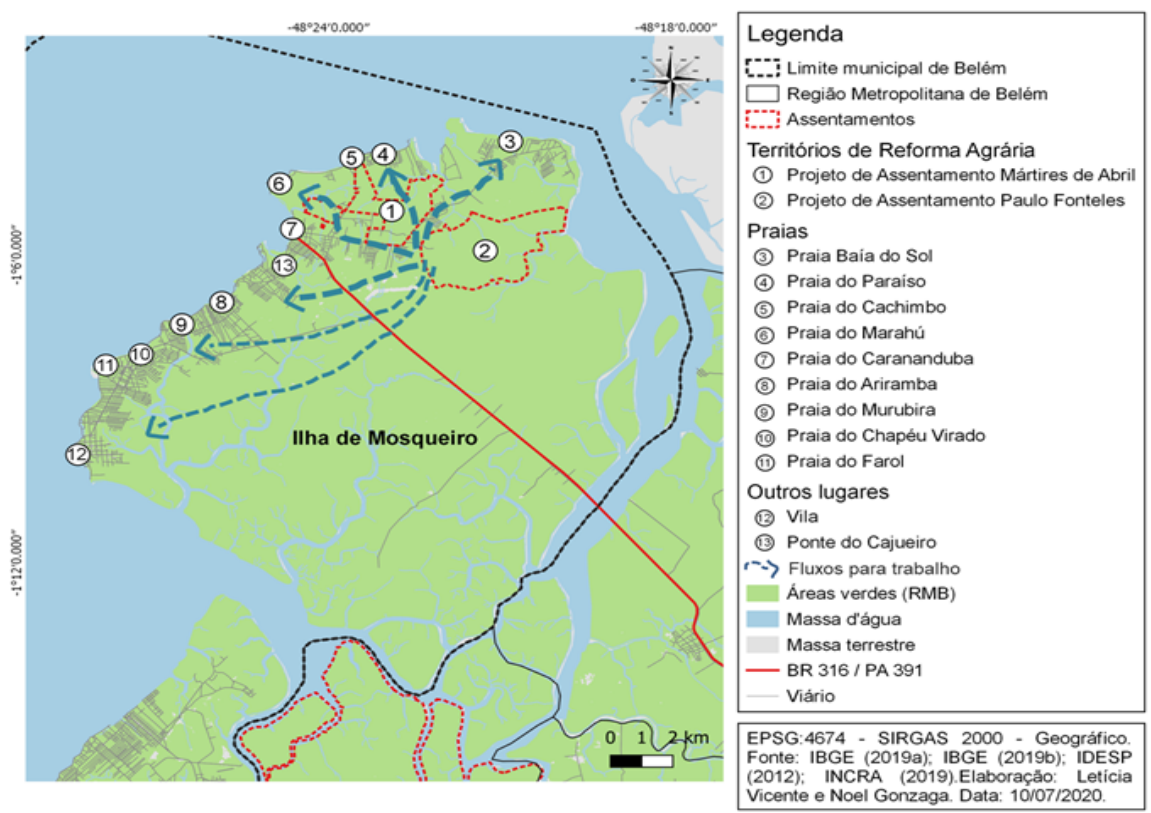


Figura 4 Localização e fluxos principais dos Assentamentos estudados. Fontes e elaboração indicados na figura.

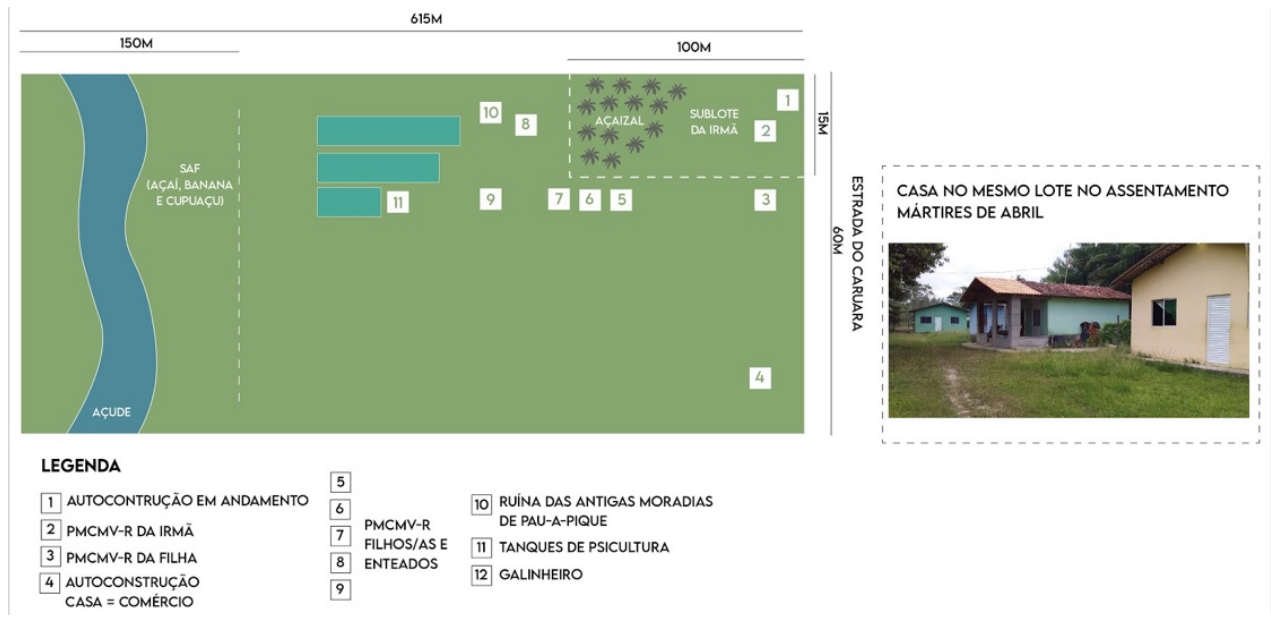

Figura 5 Aproveitamento do lote de uma família do Assentamento Paulo Fonteles. Fonte: Gonzaga, 2020. Elaboração: Elis Brazil e Noel Gonzaga.

\subsection{O território continental do Quilombo do Abacatal}

$\mathrm{Na}$ porção continental, destaca-se um mosaico de áreas protegidas ao sul da mancha urbana metropolitana, que segue uma perspectiva de conservação sem população, à exceção da comunidade do Abacatal, comunidade de herdeiros, localizada às margens do rio Uriboquinha, afluente do Guamá, município de Ananindeua, na Região Metropolitana, a $16 \mathrm{~km}$ de Belém. Segundo a historiografia, é um território doado por um Conde a uma mulher que ele escravizava, e às filhas que tiveram, em 1710 (ACEVEDO MARIN; CASTRO, 2004). No decorrer de sete gerações, a área total herdada foi bastante reduzida. Há carência de registros históricos para reconstituir este processo de encolhimento, mas relatos sobre a localização da casa do Conde dentro da Fazenda Pirelle, indicam que sua propriedade era muito maior do que é hoje. Documentos com registros fundiários da virada entre os séculos XIX e XX, mostram que essas áreas periurbanas próximas ao Rio Aurá eram reportadas como terras de Amélia Chermont em 1905 (MUNIZ, 1905).

Relato do arquiteto Cicerino Cabral (2020), presidente da Cohab durante o período de construção do complexo habitacional das Cidades Novas, informa que as terras vizinhas ao Abacatal, que hoje constituem a Fazenda Pirelli, foram oferecidas à Cohab por empresários japoneses nos anos 1970. Tratase de uma área de 7300 hectares que foi expropriada de comunidades extrativistas para produção de borracha, sob operação da Companhia Industrial Brasileira Pirelli S/A, instalada em 1920 com o objetivo de produzir matéria prima para a produção de pneus (ACEVEDO MARIN; CASTRO, 2004).

Apenas em 1998 as terras da comunidade foram tituladas e em 2012 ampliadas para a configuração atual de 308 hectares, com base no registro da sesmaria (doação) do século XVIII e nas garantias da Constituição de 1988 (ACEVEDO MARIN; CASTRO, 2004). Observe-se que isto corresponde a apenas $15 \%$ do espaço reivindicado pela comunidade (AMORAS, 2018), atualmente composta por 500 famílias. Sua condição de área rural do município de Ananindeua, segundo mais populoso do Pará, é ameaçada pela intenção oficial de construção de uma via expressa que atravesse as áreas ambientalmente protegidas conectando do centro metropolitano e a Alça Viária, complexo de rodovias e pontes que conecta por via terrestre a capital ao sul do estado. 
A regulamentação oficial do município de Ananindeua não oferece resistência às pressões por expansão urbana ou de instalação de usos ligados ao metabolismo urbano naquela parte de seu território. Desse modo o Quilombo do Abacatal foi cercado pelo Aterro (ou Lixão) do Aurá, por empreendimentos habitacionais financiados pelo programa Minha Casa Minha Vida, por áreas de exploração de minério destinado à construção civil, à instalação de uma subestação de energia elétrica de $500 \mathrm{Kv}$, conforme representado na figura 6 . A condição de isolamento e de obstáculo à realização de interesses imobiliários também atraiu a ação de milícias para o entorno da comunidade, que gradativamente intensificam ações de promoção do terror, como parte de uma estratégia de intimidação.
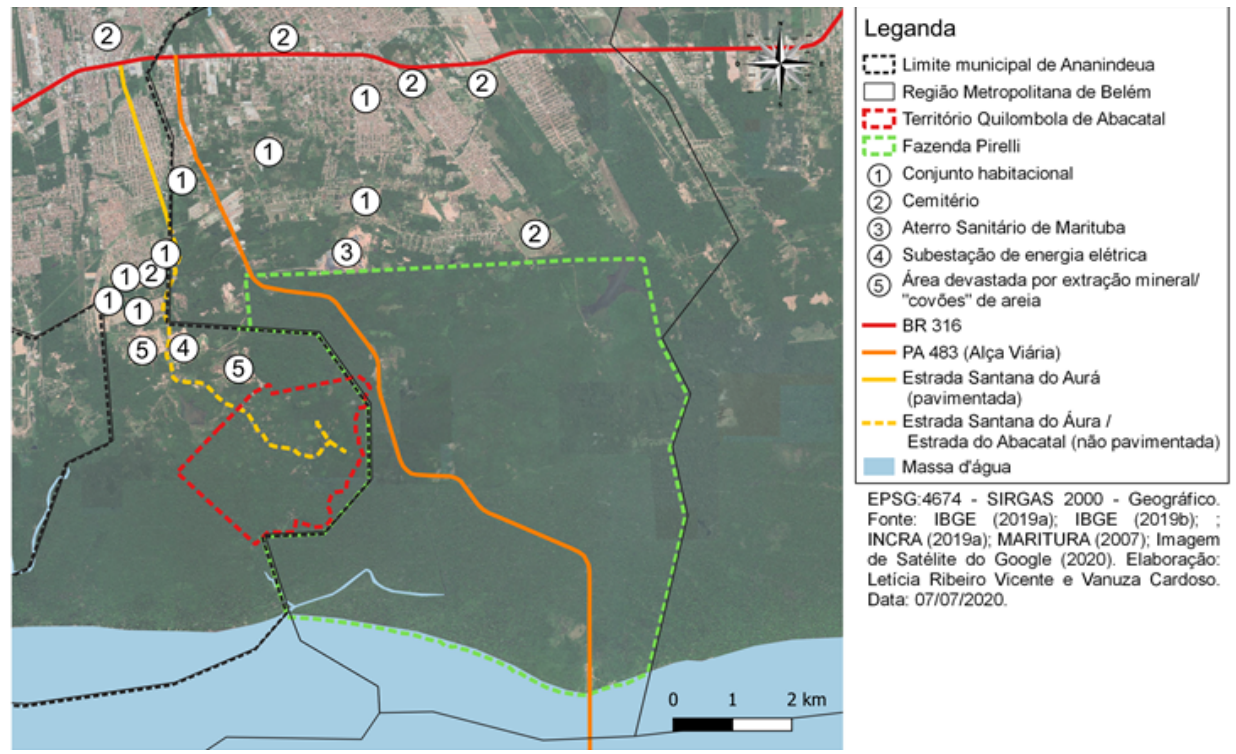

Figura 6: Espacialização das pressões que afetam o Território Quilombola do Abacatal. Fontes e elaboração indicadas na figura.

No caso desta comunidade, Amoras (2018) observa que as pressões da cidade e o descaso do poder publico são visíveis no perfil socioeconômico das famílias (escolaridade e renda baixas), a maioria se mantem com os auxílios do governo federal, aposentadorias e por meio da geração de renda (trabalho rural em pequenas roças de mandioca e trabalho precário urbano). Há séculos o Abacatal padece com ameaças ao território. Contudo, reelabora as suas estratégias de resistência acionando aquilo que preserva na sua organização social, política e espacial, como: o agrupamento em lotes coletivos que abrigam membros de uma mesma família; a manutenção de costumes e regras internos nas relações de trocas (solidariedades); o cultivo de plantas e criação de animais; casamentos entre famílias originárias (na maioria) e a organização política em uma associação dos moradores para tomadas de decisões, reivindicações e negociações com o Estado e organizações defensoras de suas lutas.. A comunidade, assim, toma na sua identificação a feição rural do território, desse modo, posiciona-se pela recusa a ser identificada como um quilombo urbano, ou área urbana. A cidade para os abacataenses, é um lugar para obtenção de serviços escassos no meio rural (tais como telefonia, transporte, saneamento, educação, saúde), servindo também de espaço de luta para acionar direitos. É importante mencionar que a Abacatal é a comunidade com o maior numero de ingressos na Universidade Federal do Pará-UFPA por meio da Política de Cotas Raciais-Processo Seletivo Especial-PSE

\section{Contexto espacial e conflitos em Santarém}


Santarém é a cidade mais importante do Oeste Paraense, que teve sua fundação portuguesa há 355 anos, mas cujo sítio teria sido ocupado há mais de dez mil anos. O lugar abrigou civilizações précabralinas portadoras de dinâmicas urbanas, cultura e organização social próprias e serviu de nó para redes que conectavam populações de diferentes territórios da Amazônia (LOPES, 2017).Com o tempo a cidade consolidou a sua localização estratégica, de ponto central entre Belém e Manaus, e se destacou como importante entreposto comercial. Sua localização privilegiada foi articulada à rede de infraestrutura logística, o que transformou a cidade em ponto de apoio à exportação de commodities, em paraíso da acumulação primitiva para o setor imobiliário articulado globalmente, e também em palco de profundas desigualdades, violências e conflitos contra a população tradicional que sempre soube como usufruir e preservar seus recursos.

Neste cenário, Santarém exemplifica um padrão de metrópole em formação incomum, onde a diversidade socioespacial reporta-se tanto ao perfil hegemônico metropolitano, quanto à origem amazônica ribeirinha; apenas $1 \%$ do município de Santarém corresponde à mancha urbana consolidada, não existe conurbação de Santarém com as cidades da sua periferia metropolitana (ver figura 2); ao invés disso, em meio às manchas urbanas, existem outros padrões de ocupação, como assentamentos extrativistas, comunidades indígenas e quilombolas, áreas de reserva, florestas, e o agronegócio (GOMES et al, 2017).

O município atravessa constantes disputas por terra e pela preservação/destruição dos recursos naturais. A pressão constante do agronegócio, desmatamento, queimadas, grilagem de terra e turismo de alto padrão ameaça o mosaico institucional que assegura a terra para outros modos de vida e outras formas de ocupação do território. Neste mosaico, os recursos naturais são preservados e há interdependência entre o padrão de ocupação, habitantes e o bioma. A segurança da terra nesse contexto garante a reprodução das práticas tradicionais, possibilita a geração de renda e fortalece os movimentos de preservação ambiental. Em um cenário reverso de falta de segurança da terra, que vem sendo estabelecido com a extinção dos assentamentos especiais e rurais por efeito da Lei Federal no.13465/2017 (BRASIL, 2017), essa população migra para as áreas urbanas, reproduzindo um padrão precário de ocupação do território e de exclusão socioeconômica (REIS, RODRIGUES, 2019).

Outro aspecto relevante é a pressão da indústria do turismo sobre o Território de Alter do Chão, reconhecida pelo povo indígena Borari como uma aldeia (RODRIGUES, 2020). Os Borari reivindicam uma extensão da terra que se sobrepõe à APA de Alter do Chão e a parte do PAE Eixo Forte (ver poligonal azul na figura 2), para constituir a Terra Indígena Borari. Muitas vilas do assentamento são habitadas por famílias indígenas, que desde a abertura das estradas, da implantação de uma logística de apoio às exportações e à difusão internacional da região como Caribe de água doce, sofrem apagamento de suas identidades étnicas, face ao agravamento dos conflitos. Contra esse processo histórico de apagamento se organizou nessa região um processo crescente de territorialização de povos indígenas, iniciado ainda no final da década de 1990, que reivindicado o (re)conhecimento de diferentes etnias que estão se auto afirmando em seus territórios tradicionalmente ocupados. Tais povos indígenas se organizam em associações, conselhos e por territorialidades específicas segundo seus grupos étnicos e os territórios reivindicados. (COSTA, 2019). No levantamento realizado em 2014 esse grupo era composto por sessenta e quatro aldeias/comunidades de treze etnias: Arara Vermelha-Tupaiu, Munduruku, Arapiun, Jaraqui, Tapajó, Borari, Munduruku-Apiaká, Tupinambá, Munduruku-Cara Preta, Maitapu, Yawaretê, Kumaruara, Tapuia (CADERNO 1, 2014).

No caso de Alter do Chão, apesar da coalizão entre segmentos das elites locais e internacionais, para impor um padrão de ocupação do território baseado na grande aglomeração, no consumo excessivo, na matriz rodoviária, na exclusão social e degradação ambiental, apesar da capacidade milenar dos povos nativos manejarem a natureza, e contribuírem para a reprodução da biodiversidade (CARDOSO, OLIVEIRA, GOMES, 2020), a organização dos indígenas conta com um cacicado de mulheres e duas 
associações que defendem o Território do Povo Borari e manutenção do seu modo de vida (RODRIGUES, 2021).

\section{Considerações finais}

A construção de cartografias a partir dos processos informados pelas comunidades revela a existência de conflitos diversos, e de práticas de resistência para enfrentá-los, que perpassam dimensões materiais e imateriais. Todavia, os conflitos resultam em perda do espaço habitado no decorrer do tempo, que nesses casos é também o espaço do sustento, e contribuem para o abandono do modo de vida, e inserção dos habitantes dessas comunidades como subalternos na sociedade urbana.

As ferramentas de geoprocessamento quando utilizadas em associação com a escuta ativa podem contribuir para na afirmação identitária desses grupos, oferecendo-Ihes novas perspectivas do processo espacial e a possibilidade de insurgência efetiva contra as pressões dos agentes vinculados aos setores do turismo e imobiliário, ávidos consumidores de territórios periurbanos.

Ao situarem espacialmente os processos de luta e pressão, as contra-cartografias geram maior visibilidade de atores que são propositalmente apagados nas cartografias oficiais ou hegemônicas, na medida em que as políticas públicas consideram as bordas como espaços abertos, disponíveis para conversão de uso e ocupação do solo, apesar da diversidade social e ambiental que abrigam. As contra-cartografias potencializam a articulação sistêmica das práticas concretas das comunidades periurbanas às demandas do século XXI, por capacidade de adaptação às crises ambientais, sanitárias, políticas e econômicas e de oferecer mediações entre modos de vida que coexistem na região. No contexto estudado observou-se que esta resiliência tem sido o marcador da resistência, e que ela precisa transcender esta condição para, então, alavancar e potencializar os enfrentamentos necessários para a conquista de condição digna de existir, em uma região rica e diversa, social e biologicamente, como a Amazônia.

\section{Referências:}

ACEVEDO-MARIN, Rosa.; CASTRO, Edna. No caminho de pedras de Abacatal: experiências sociais de negros no Para. Belém: Nucleo de Altos Estudos Amazônicos, 2004.

AMORAS, Maria. "Temos um jeito de viver aqui”: identificação quilombola pelas crianças abacataenses. Temáticas, Campinas, 26, (51): 53-86, fev./jun. 2018.

ALMEIRA, Alfredo 2002. Os quilombos e as novas etnias. In: O'DWYER, E. C. (Org.). Quilombos: identidade étnica e territorialidade. Rio de Janeiro: FGV, 2002.

ALMEIDA, Alfredo. "Terras tradicionalmente ocupadas - processos de territorialização e movimentos sociais". Revista Brasileira de Estudos Urbanos e Regionais. Vol. 6, no 1. 2004: 9-32.

ALMEIDA, Alfredo. Mapas e Museus: uma nova cartografia social. Revista Ciência e Cultura. vol.70 no.4, 2018, 58-61.http://dx.doi.org/10.21800/2317-66602018000400016.

ALMEIDA, Alfredo. "Terras de quilombo, terras indígenas, 'babaçuais livres', 'castanhais do povo', faxinais e fundos de pasto: Terras tradicionalmente ocupadas". Manaus: PPGSCA-UFAM, Fundação Ford, 2006. 
ALMEIDA, Alfredo. Antropologia dos arquivos da Amazônia. Rio de Janeiro: Casa 8/ Fundação Universidade da Amazônia, 2008.

ALMEIDA, Alfredo.; DOURADO, Sheila.; BERTOLINI,Carolina. A New Social Cartography. Defending Traditional Territories by Mapping in the Amazon.In: HALDER, Severin. MICHEL, Boris (orgs) This is not an Atlas - A Global Collection of Counter- Cartographies. Dusseldorf: Transcript, 2018.

ARES, Pablo.; RISLER, Julia. Manual de mapeocolectivo: recursos cartográficos para processos territoriais de creación colaborativa. Buenos Aires: Tinta Limón, 2013.

BALLESTRIN, Luciana. A América Latina e o giro decolonial. Revista Brasileira de Ciência Política, n. 11, p. 89-117, 2013.

BARTOLI, Estevan. Cidades na Amazônia, sistemas territoriais e a rede urbana. Revista Mercator, v. 17, 2018.

BECKER, Bertha. Geopolítica da Amazônia. Estudos avançados, v. 19, n. 53, p. 71-86, 2005.

BERCKER, Bertha. Urbe Amazônida. Rio de Janeiro: Garamond, 2013.

BHABHA, Homi . O local da cultura. Belo Horizonte: Ed. UFMG, 1998.

BRASIL. Lei № 13465, de 11 de julho de 2017. Dispõe sobre a regularização fundiária rural e urbana, sobre a liquidação de créditos concedidos aos assentados da reforma agrária e sobre a regularização fundiária no âmbito da Amazônia Legal. Brasil, 2017.

BRITO, Romario. Esse rio é minha rua... e a floresta, a minha casa: guia de desenho ribeirinho para a llha do Combu, Belém, Pará. Monografia (Trabalho de conclusão de curso em Arquitetura e Urbanismo) Universidade Federal do Pará. Belém, 2019.

CABRAL, Cicerino. Entrevista concedida à [omitido para não identificar autores] em dezembro de 2020.

CADERNO NOVA CARTOGRAFIA. Mapeamento Social como Instrumento de Gestão Territorial contra o Desmatamento e a Devastação: processo de capacitação de povos e comunidades tradicionais. N. 1 (jun. 2014), Manaus: UEA Edições, 2014.

CAMPOS, Thiago. Retomar a terra: como ser indígena na região metropolitana de Belo Horizonte. Dissertação de Mestrado. Programa de Pós-Graduação em Arquitetura e Urbanismo. Universidade Federal de Minas Gerais, 2019.

CARDOSO, Ana Claudia; MELO, Ana Carolina. ; GOMES, Taynara. O urbano contemporâneo na fronteira de expansão do capital: padrões de transformações espaciais em seis cidades do Pará, Brasil. Revista de Morfologia Urbana, v.4, n. 1, p. 5-28, 2017.

CARDOSO , Ana Claudia; SILVA, Harley.; MELO, Ana Carolina; FERNANDES, Danilo. Urban Troplical Forest: where nature and human settlements are assets for overcoming dependency, but how can urbanisation theories identify these potentials? In: Horn, P et al (orgs) Emerging Urban Spaces. Cham: Springer, 2018, p. 177-200.

CARDOSO, Ana Claudia; OLIVEIRA, Kamila; GOMES, Taynara.Mismatches between extended urbanization and everyday socioenvironmental conflicts in Santarém, Pará, Brazil. Sustainability in Debate, v. 11, n.1, p 83-97,2020.

CARDOSO, Ana Claudia.; BRAZIL, Elis ;CARDOSO, Cristina. Proposta de Trama Cabocla para Cidades Amazônicas. Anais do VI Enanparq. Brasília: UnB, 2021.

COSTA, Francisco. A Brief Economic History of Amazon (1720-1970). London: Cambridge Scholars Publishing, 2019. 
COSTA, E. Relatório de Pesquisa - Ilha do Maracujá.Projeto "Alternativas de Desenvolvimento: cartografia social de territórios de populações tradicionais do Pará e Minas Gerais". Belém: UFPA, 2020 (não publicado).

COSTA, S. Violência, Discriminação, Racismo e Conflitos Envolvendo os Povos Indígenas do Baixo Tapajós. Temporalis, Brasília (DF), ano 19, n. 38, p. 87-100, jul./dez. 2019.

CRUZ, Valter. Movimentos sociais, identidades coletivas e lutas pelo direito ao território na Amazônia. In: SILVA, Onildo; SANTOS, Edinuzia; COELHO NETO, Agripino. (Org.). Identidade, Território e Resistência. Rio de Janeiro: Consequência, 2014, v. 1, p. 37-72.

CUSICANQUI, Silvia. Sociología de la Imagem. Miradas ch'ixi desde la historia andina. Buenos Aires: Tinta Limón, 2015.

CUNHA, Manuela \& ALMEIDA, Mauro. Populações tradicionais e conservação ambiental. São Paulo: Estação Liberdade: Instituto Socioambiental, 2001.

GOMES, T. V., CARDOSO, A. C. D. (2019). Santarém: o ponto de partida para o (ou de retorno) urbano utopia. Urbe, 11, e20170219. https://doi.org/10.1590/2175-3369.011.001.AO03

GOMES, T. ; CARDOSO, A.C.; COELHO, H.; OLIVEIRA, K. Santarém (PA): um caso de espaço metropolitano sob múltiplas determinações. Cadernos Metrópole, São Paulo, v. 19, n. 40, pp. 891-918, set/dez 2017 http://dx.doi.org/10.1590/2236-9996.2017-4009.

GONZAGA, N. Relatório de Pesquisa - Assentamentos Paulo Fonteles e Mártires de Abril. Projeto "Alternativas de Desenvolvimento: cartografia social de territórios de populações tradicionais do Pará e Minas Gerais”.Belém: UFPA, 2020. (não publicado)

HALDER, Severin; MICHEL, Boris (orgs) This is not an Atlas - A Global Collection of CounterCartographies.Dusseldorf: Transcript, 2018.

LOPES, José. 1499: O Brasil antes de Cabral. São Paulo: HapperCollins, 2017.

LEÃO, Richard. Cenários da informalidade na Amazônia: estudos sobre o mercado de trabalho informal na capital do meio do mundo-Macapá (AP). Tese de doutorado em Ciências Sociais, Unesp, Araraquara, 2020.

MBEMBE, Achille. Necropolítica. São Paulo: mbremN-1, 2019.

MIRANDA, Thales. A llusão da Igualdade. Natureza, justiça ambiental e racismo em Belém. Dissertação de Mestrado. Programa de Pós-Graduação em Arquitetura e Urbanismo. Universidade Federal do Pará, 2020.

MONTE-MOR, Roberto; GOMES, Ana. Duas décadas de pesquisa com os Xakriabá do Norte de Minas: do diagnóstico da economia ao monitoramento da pandemia da Covid-19. Nova Economia, [S. I.], v. 30, n. 3 , p. 747-769, 2021. Disponível em: https://revistas.face.ufmg.br/index.php/novaeconomia/article/view/6509. Acesso em: 23 nov. 2021.

MUNIZ, Palma. Mapa de Belém e Terrenos Adjacentes. Patrimônios dos Conselhos Municipaes do Estado do Pará. Belém: Comissão Demarcadora de Limites, 1905.

OCAÑA, Alexander.; LÓPEZ, Maria Isabel, 2019. Hacerdecolonial: desobedecer a lametodología de investigación. Hallazgos, 16(31), 147-166.

REIS, Ana Beatriz.; RODRIGUES, Yuri. (orgs) A luta pelo direito à cidade na Amazônia, o processo de revisão do Plano Diretor de Santarém (PA). Santarém: FASE, 2019. 
RODRIGUES, Yuri. Relatório de Pesquisa - Alter do Chão e PAE Eixo Forte.Projeto"Alternativas de Desenvolvimento: cartografia social de territórios de populações tradicionais do Pará e Minas Gerais".Belém: UFPA, 2020. (não publicado)

SANTOS, Milton. O território e o saber local. Cadernos IPPUR, Rio de Janeiro, ano XIII, n² 2, 1999, pp.1520.

SANTOS, Milton. Por uma outra globalização. Do pensamento único à consciência universal. Record, Rio de Janeiro, 2000.

SARGES, Maria de Nazaré, Memórias do "velho" intendente:Antonio Lemos - 1869-1973..Tese (Doutorado em História) - Instituto de Filosofia e Ciências Humanas, Universidade Estadual de Campinas, 1998.

SILVA, Harley; DINIZ, Sibelle; FERREIRA, Vanessa. Circuitos da Economia Urbana e economia dos setores populares na fronteira amazônica: o cenário atual no sudeste do Pará. Revista Brasileira de Estudos Urbanos e Regionais, v. 15, n. 2, p. 61-61, 2013.

SILVA, Marlon; TOURINHO,Helena. Território, territorialidade e fronteira: o problema dos limites municipais e seus desdobramentos em Belém/PA. Urbe, 9(1), 96-109, jan./abr. 2017.

VICENTE, Letícia. Do (Outro) lado do Rio: Proposta de Ordenamento Territorial para a llha de Cotijuba Belém $(\mathrm{Pa})$. Trabalho de Conclusão de Curso, monografia. Faculdade de Arquitetura e Urbanismo. Universidade Federal do Pará,2019. 